\title{
A COORDENAÇÃO FEDERATIVA DE POLÍTICAS PÚBLICAS: UMA ANÁLISE DAS POLÍTICAS BRASILEIRAS NAS ÚLTIMAS DÉCADAS
}

\author{
PUBLIC POLICY FEDERATIVE COORDINATION: AN ANALYSIS OF BRAZILIAN POLICIES IN RECENT DECADES \\ COORDINACIÓN FEDERAL DE POLÍTICAS PÚBLICAS: UN ANÁLISIS DE LAS POLÍTICAS BRASILEÑAS EN LAS ÚLTIMAS DÉCADAS
}

Resumo

Este artigo apresenta o panorama do processo de coordenação de políticas por parte do governo federal no período da pré-Constituição Federal/88 e entre 1988-2012, contribuindo para explicitar, de modo empírico, a dupla tendência presente no contexto federativo brasileiro: transferência de recursos e descentralização de competências e de coordenação federal das políticas. Parte-se da revisão da literatura em que se fundamenta esse debate, acerca dos impactos e resultados do processo de descentralização de políticas sociais no modelo federativo brasileiro desde a promulgação da Constituição Federal (CF) de 1988. Em seguida, sistematiza-se a evolução de nove políticas públicas com ênfase em quatro marcos temporais: antes de 1988, as mudanças introduzidas pela CF de 1988, os movimentos ocorridos ao longo da década de 1990 e os anos 2000. Por fim, apresenta-se uma síntese do panorama atual das políticas a partir de categorias de análise que permitem identificar, no contexto federativo brasileiro, uma tendência geral de coordenação por parte do governo federal.

Palavras-chave: Federalismo, políticas públicas, coordenação federativa, descentralização, relações federativas

Gabriela Spanghero Lotta - gabriela.lotta@gmail.com

Doutora em Ciência Política pela USP, mestre e graduada em administração pública pela FGV. Professora do curso de Políticas

Públicas da UFABC.

Renata Gonçalves - rerochagon@uol.com.br

Mestre em administração pública pela FGV, Ministério das Cidades.

Marina Bitelman - marina.bitelman@gmail.com

mestre em administração pública pela FGV

Artigo submetido no dia 04.10.2012 e aprovado em 16.04.2014

\section{Abstract}

Public Policy Federative Coordination: An Analysis of Brazilian policies in recent decades

This article presents an overview of the current process of policy coordination conduced by Brazilian federal qovernment in the period before Brazilian Federal Constitution (1988) and the period after it (1988-2012). The paper aims to explain, empirically, a dual approach in this federal Brazilian context: transfer of resources and decentralization of responsibilities and coordination of federal policies. It begins with a literature review in which it appears that debate, about the impacts and outcomes of decentralization of social policies in the model from the Brazilian federal enactment of the Federal Constitution of 1988. Then systematizes the evolution of nine public policies, focusing on four time frames: before 1988, changes introduced by the 1988 Constitution, the movements during the 1990s and the present moment, especially since 2000. Finally, it presents an overview of the current situation of policies, based on the categories of analysis to identify, in Brazilian federal context, a general trend of coordination conduced by the federal government.

Key words: federalism, public policies, federal coordination, descentralization, federal relationships. 


\section{Resumen}

El presente artículo presenta el panorama del proceso de coordinación de políticas por parte del Gobierno Federal en el periodo previo a la Constitución Federal de 1988, y a continuación, entre 19882012, contribuyendo a explicitar, de modo empírico, una doble tendencia presente en el contexto federal brasileño - de transferencia de recursos y descentralización de competencias y de coordinación federal de las políticas. De parte de la revisión de la literatura en la que se inserta este debate, acerca de los impactos y resultados del proceso de descentralización de políticas sociales en el modelo federal brasileño a partir de la promulgación de la Constitución Federal (CF) de 1988. Luego, se sistematiza la evolución de nueve políticas públicas, centrándose en cuatro marcos temporales: antes de 1988, los cambios introducidos por la CF de 1988, los movimientos que se sucedieron a lo largo de la década de 1990 y los años 2000. Por último, se presenta una síntesis del panorama actual de las políticas, a partir de categorías de análisis que permiten identificar, en el contexto federal brasileño, una tendencia general de coordinación por parte del gobierno federal.

Palabras clave: federalismo, políticas públicas, coordinación federal, descentralización, relaciones federales

\section{INTRODUÇÃO}

$\mathrm{Na}$ literatura brasileira, diversos autores têm analisado o processo de descentralização de políticas públicas promovido a partir da Constituição Federal (CF) de 1988 e ao longo da década seguinte, verificando que isso produziu distintos resultados ao longo do território nacional, tanto entre os estados e municípios, como entre as políticas (Arretche, 1999; Almeida, 2000 e 2005).

Junto a essa tendência descentralizadora, parte da literatura observa, sobretudo recentemente, uma tendência, por parte do governo federal, de coordenação federativa na maioria das áreas de políticas sociais (Abrucio, 2005), também identificada por outros autores como um processo de recentralização (Almeida, 2005; Arretche, 2005). Esse movimento de coordenação, que pode ser observado em algumas políticas desde a década de 1990 e, em outras, a partir dos anos 2000, expressa-se na formulação de políticas, programas e planos nacionais, assim como na constituição de sistemas únicos, em que se busca a integração das ações dos diferentes entes governamentais. Como se verá, esses programas, planos e sistemas, em sua maioria, propõem a estruturação de políticas nacionais a partir de princípios de transferência de recursos e descentralização de ações coordenadas pelo governo federal, o qual, em geral, exige contrapartidas dos entes subnacionais, oferece incentivos e promove induções que interferem na distribuição das competências dentro da federação.

Entretanto, os diversos planos e sistemas nacionais de políticas setoriais discutidos ou aprovados recentemente não estão ainda retratados na literatura de forma sistematizada. Assim, este artigo sistematiza e apresenta um panorama do modelo atual de nove políticas públicas, buscando explicitar, de modo empírico, a dupla tendência presente no contexto federativo brasileiro (transferência de recursos e descentralização de competências), juntamente com a coordenação, realizada pelo governo central, das políticas nos três níveis da federação.

Além desta introdução, em que são apresentados os objetivos pretendidos $\mathrm{e}$ a metodologia utilizada, o artigo se divide em três seções. Na primeira, apresentase uma breve revisão da literatura, em que são discutidos os impactos e resultados do processo de descentralização de políticas sociais no modelo federativo brasileiro a partir da promulgação da Constituição Federal de 
1988 e sua importância ao longo do território nacional. Na segunda seção, apresenta-se a evolução de nove políticas públicas: Saúde, Educação, Assistência Social, Combate à Pobreza, Habitação, Saneamento, Segurança Pública, Meio Ambiente e Cultura, com ênfase em quatro marcos distintos de temporalidade: a estrutura das políticas até 1988 , as mudanças introduzidas pela Constituição Federal de 1988, os movimentos ocorridos ao longo da década de 1990 e, mais recentemente, a primeira década dos anos 2000. ${ }^{1}$

A metodologia empregada na análise consistiu, inicialmente, em uma breve apresentação da evolução de cada uma das políticas, ao longo da temporalidade descrita, quanto à presença de normas regulamentadoras e de formas de distribuição de competências entre os níveis de governo e fontes de financiamento. Em seguida, apresenta-se uma síntese do panorama atual das políticas, utilizando as seguintes categorias de análise: formas institucionais de coordenação federativa (sistemas, políticas, programas ou planos nacionais); princípios; distribuição de competências e atribuições entre os níveis de governos; fontes de financiamento e formas de repasse de recursos; normas regulamentadoras e data de aprovação; formas de adesão dos entes subnacionais propostas pelo governo federal; existência de vinculação constitucional; existência de sistemas de monitoramento e avaliação; agentes envolvidos na política; presença de tipos de enquadramento de gestão dos entes subnacionais, e característica síntese da política. O trabalho foi desenvolvido a partir de revisão da literatura, estudo das diferentes legislações, normas e textos das políticas e análise comparativa deles, considerando, para tanto, as descrições formais dos programas.

Por fim, na terceira seção, analisase o padrão de cada uma das políticas nos anos 2000 com o propósito de destacar a tendência geral verificada nas políticas públicas no Brasil, e são apresentadas algumas considerações finais sobre os principais achados deste trabalho.

\section{Descentralização com coordenação?}

A partir da promulgação da Constituição Federal de 1988 e ao longo da década de 1990, o contexto institucional brasileiro foi marcado por significativas transformações, sobretudo no eixo das políticas sociais, cujas transformações estão associadas à transferência de um conjunto expressivo de atribuições e competências para os níveis subnacionais de governo. Parte da literatura atribui o movimento de descentralização das políticas públicas no Brasil à luta pela democracia dos anos 1970 e 1980, em oposição ao período do regime militar, caracterizado pela excessiva centralização no governo federal que teria produzido ineficiência, corrupção e ausência de participação no processo decisório (Arretche, 1996). Desde a Constituinte, "o país vive um processo de construção das instituições de um federalismo cooperativo e descentralizado, que supõe competências compartilhadas e um processo permanente de negociação dos termos de cooperação" (Almeida, 2000:1).

Ao longo da década de 1990, os princípios constitucionais foram se consolidando a partir da promulgação de leis e normas que reforçaram a tendência à descentralização na maioria das áreas de política social. A partir do primeiro Governo Fernando Henrique Cardoso, houve uma alteração da distribuição de competências entre municípios, estados e governo federal para provisão de serviços sociais, 
sobretudo no sentido da municipalização, como no caso da saúde, em que a totalidade dos serviços de atenção básica foi transferida para os municípios, e da educação, na qual houve municipalização significativa da oferta de matrícula no ensino fundamental (Arretche, 2002).

Nesse processo, incentivou-se a participação direta de estados e municípios na implementação de políticas originalmente executadaspelogovernocentral, transferindose para os governos subnacionais a gestão e a prestação de serviços em setores como a educação e a saúde. No entanto, como evidencia Arretche (2012), esse processo de descentralização veio combinado com uma tentativa de não diminuir a importância estratégica do poder central em relação a seu papel redistributivo (Faria, 2003), à sua capacidade de arrecadação tributária e, especialmente, a seu poder de coordenação das políticas que envolvem outros entes federativos.

De modo geral, a coordenação pode ser definida como o processo de criação ou utilização de regras de decisão pelas quais diferentes atores se ocupam coletivamente de um mesmo campo (Ariznabarreta, 2001), o que, no caso das políticas sociais brasileiras, se concretiza com o governo federal normatizando-as e financiando-as e, na maioria das vezes, os governos estaduais e municipais implementando as ações.

Segundo Souza (2004), as novas políticas voltadas para a municipalização adotadas no final dos anos 1990 tiveram suas motivações diversas daquelas que prevaleceram no processo constituinte, uma vez que seu principal decisor e indutor foi o próprio governo federal. A autora analisa que, no processo brasileiro de descentralização e implementação de políticas de municipalização de programas sociais universais, um fator fundamental a ser observado foi o compromisso (e a efetiva realização) do governo federal de liberar regularmente os recursos acordados. Além desse fator, ela aponta que é importante ressaltar $o$ desenho institucional das políticas, o aspecto de que a transferência de recursos foi pautada por mecanismos que envolvem recompensas e sanções relacionadas à adesão dos municípios, como também o estabelecimento de regras claras e universais. No entanto, em países marcados por alto grau de heterogeneidade, como é o caso do Brasil, a descentralização apresenta resultados contraditórios e cria novas tensões para problemas já existentes, como os das expressivas desigualdades inter e intrarregionais (Souza, 2002).

Segundo Souza e Carvalho (1999), as desigualdades existentes no país se refletem em significativas diferenças nas condições financeiras, institucionais, políticas e técnicoadministrativas dos entes subnacionais, interferindo diretamente em sua capacidade de resposta às necessidades e demandas da população. Sobretudo na esfera local, tais heterogeneidades revelam que a maior parte dos municípios brasileiros, de reduzido porte, depende fortemente do governo federal e dos governos estaduais. Ainda segundo as autoras, na década de 1990, essa dependência teria aumentado, o que contribuiu para a redução da autonomia e da capacidade de atuação dos estados e municípios, aumentando sua dependência em relação ao poder central e, sobretudo, reforçando as desigualdades municipais inter e intrarregionais.

Alguns argumentos são apresentados por Arretche (1996) para problematizar e demonstrar que várias das associações positivas acerca da descentralização consensuadas na década de 1980 não se 
sustentam. Cabe destacar aqui o argumento defendido pela autora que aponta que, ao contrário da ideia de que a descentralização implicaria o esvaziamento das funções do nível central de governo, reduzindo seu escopo de atuação, o sucesso da descentralização depende sobretudo da redefinição do papel estratégico do governo federal em um novo arranjo federativo. De acordo com ela, a supremacia da União, mesmo em um contexto de incentivos à descentralização, estava colocada na própria CF de 1988, que transferiu, de modo geral, apenas a execução das políticas para estados e municípios, mantendo ainda o poder do governo federal para normatização e financiamento da maioria das políticas. Analisando as competências constitucionais, a autora conclui que o governo federal "tem autoridade regulatória para influir decisivamente na agenda política dos governos subnacionais" (Arretche, 2012:17).

De fato, em concomitância à tendência descentralizadora reforçada pela Constituição de 1988, especialmente a partir da metade da década de 1990, ocorreram movimentos centralizadores, tanto referentes à regulação das relações fiscais entre os níveis de governo quanto à redefinição das responsabilidades na provisão de serviços sociais, produzindo-se um arranjo complexo em que coexistem tendências centralizadoras e descentralizadoras no cenário federativo brasileiro (Almeida, 2005).

Embora a literatura apresente argumentos distintos para esse movimento, seja analisando-o como tendência em direção à recentralização, seja em direção à coordenação, fala-se aqui de um movimento de fortalecimento do governo federal no sentido de coordenar políticas e diretrizes nacionais a serem implementadas pelos estados e municípios, considerando padrões comuns de ações e repasses de recursos a elas, além de incentivos e induções para a adesão dos entes às políticas desenhadas e coordenadas em nível federal.

Os incentivos poderiam ser caracterizados como vantagens destinadas a estimular o desenvolvimento de determinadas ações e a realização de objetivos, concedidas, no caso, pela União a outros entes subnacionais, por meios tributários e outros. A indução envolve iniciativas que buscam provocar ou iniciar ações, para que certo objetivo esperado se realize. A adesão dos entes subnacionais a uma determinada política, programa ou sistema pode ser voluntária ou coercitiva, e os incentivos, por sua vez, podem representar soluções atraentes para estados e municípios, mas, em geral, são repassados pela União mediante condicionalidades preestabelecidas.

Sobre esse processo, como analisado por Almeida (2000), a literatura aponta um movimento - já nos finais da década de 1990 - de recentralização ou de coordenação federativa na busca de formas eficientes para enfrentar a pobreza extrema, buscandose evitar a instrumentalização clientelista de programas pelas elites locais. A autora afirma que é possível perceber diferentes graus de descentralização e cooperação, ao mesmo tempo em que em algumas áreas reintroduziram a centralização da decisão, os recursos e a implementação na esfera federal. Para Arretche (2008), esse processo de recentralização teve o propósito de construir patamares homogêneos de políticas públicas para estados e municípios, considerando-se a dificuldade de alguns municípios, durante os anos 1990, de investirem em algumas áreas de políticas públicas. Ao longo desse processo, afirma a autora, em muitas áreas de políticas sociais, os municípios deixaram de tomar decisões sobre macropolíticas e passaram 
a ser executores de decisões tomadas em nível federal, a partir de regulações e contrapartidas estabelecidas.

Arretche (2005) também afirma que, por um lado, maiores graus de autonomia dão aos entes subnacionais a possibilidade de não aderirem às políticas federais, diminuindo o poder do governo central de colocar em prática os programas federais que envolvem estados e municípios; contudo, por outro lado, a dependência de estados e municípios fracos exige que a União despenda maiores esforços e transferências para alcançar seus objetivos. Nesses casos, ao menos, como aponta a autora, governos sem capacidade para arrecadar tributos em montante suficiente para suprir as demandas de seus cidadãos "tendem a incorporar à sua agenda as orientações políticas do nível de governo que de fato tem controle sobre tais recursos"; além de que, ainda que tenham recursos, podem "dispor de limitada autonomia para definir sua própria agenda, porque suas políticas são financiadas basicamente com transferências vinculadas" (Arretche, 2005).

As transferências federais são hoje a principal fonte de receita dos governos locais e, em segundo lugar, as transferências condicionadas universais. Ambas as formas acabam operando para reduzir desigualdades de receita entre as unidades federativas e criar incentivos com o objetivo de alinhar as prioridades dos governos locais às do governo federal. Como resultado dessas transferências, argumenta Arretche (2012), as prioridades de gastos dos governos municipais não têm comportamento caótico, mas seguem um padrão previsível com base na regulação federal. É possível, portanto, nesse contexto, combinar a execução descentralizada de serviços públicos com a centralização de autoridade sobre as regras de execução.
Com a redemocratização, a descentralização de políticas passa a depender da adesão dos níveis de governo subnacionais, eojogo federativo de barganhas, negociações, coalizões e induções das esferas superiores de poder, exigindo processos de coordenação intergovernamental (Abrucio, 2005). Segundo Abrucio (2005), nos últimos anos, a complexidade das relações intergovernamentais aumentou, sobretudo devido à convivência de tendências conflituosas, entre as quais se destacam: maior exigência ao desempenho dos governos, com fortes pressões por economia, eficiência e efetividade; aumento da demanda por autonomia de governos locais e/ou grupos étnicos, somado ao fato de que governos e coalizões nacionais se deparam com a necessidade de enfrentamento de problemas causados pela fragmentação, e urgência de reforço das instâncias nacionais para organizar melhor a inserção internacional do país e reduzir os aspectos negativos da globalização, quando, por outro lado, também aumenta a interface dos governos locais com outras estruturas de poder que não os governos centrais.

Nos primeiros anos do Governo Lula, algumas ações institucionais foram iniciadas em relação à coordenação federativa, conforme destaca Abrucio (2005), as quais abrangem o fortalecimento da Secretaria de Assuntos Federativos, a criação do Ministério das Cidades, unificando as políticas urbanas em um só órgão, e a reestruturação da política regional, com o Ministério da Integração Nacional.

Assim, esses conflitos e dilemas colocam a coordenação federativa como uma questão fundamental para as políticas sociais, implicando a discussão de questões que vão além da dicotomia centralização versus descentralização. Nesse sentido, 
torna-se necessária a busca por caminhos que possibilitem melhor adequação e equilíbrio entre competição e cooperação, entre o governo central e os demais níveis e governo. Considerando esse debate da literatura, a seguir são apresentadas e analisadas nove políticas sociais, a fim de se observar como essa possível coordenação federativa tem se efetivado, levando em conta as mudanças históricas e institucionais das políticas, bem como a distribuição de autoridade sobre a normatização e regulamentação atuais.

\section{As políticas sociais duas décadas após a Constituição Federal de 1988}

Como mencionado, a CF de 1988 constituiu um importante marco institucional no contexto federativo brasileiro, cujos impactos e transformações foram se desdobrando ao longo das duas últimas décadas. Entre as várias mudanças introduzidas, destaca-se a definição de competências exclusivas, privativas e principiológicas combinadas a competências comuns e concorrentes, repartidas de acordo com o princípio da predominância do interesse. A essa separação de campos específicos, combinam-se ainda possibilidades de delegação, áreas comuns em que se prevêem atuações paralelas da União, estados, DF e municípios, e setores concorrentes entre União e estados em que a competência para estabelecer políticas, diretrizes ou normas gerais cabe à União, enquanto se confere aos estados, ou mesmo aos municípios, competência suplementar (Silva, 2008).

No tocante à maioria das políticas sociais, a CF definiu competências comuns à União, aos estados e aos municípios nas áreas de saúde, assistência social, educação, cultura, habitação e saneamento, meio ambiente, proteção do patrimônio histórico, combate à pobreza e integração social dos setores desfavorecidos e educação para o trânsito (art. 23). Foram estabelecidas competências concorrentes aos governos federal e estaduais em áreas como proteção ao meio ambiente e aos recursos naturais, conservação do patrimônio cultural, artístico e histórico, saúde e previdência social (art. 24). A partir da CF, a "tendência à descentralização se impôs em todas as áreas de política social, exceto previdência e ciência e tecnologia, que continuaram basicamente sob responsabilidade federal.' (Almeida, 2000:4).

A seguir, apresenta-se, de maneira sistematizada, com base nos marcos de temporalidade, a evolução de cada uma das políticas quanto à presença de normas regulamentadoras, formas de distribuição de competências entre os níveis de governo e fontes de financiamento. 
Gabriela Spanghero Lotta - Renata Gonçalves - Marina Bitelman

\section{Saúde}

\begin{tabular}{|c|c|c|c|}
\hline \multirow{2}{*}{ Antes de $1988^{1}$} & \multirow{2}{*}{ CF de $1988^{1}$} & \multicolumn{2}{|c|}{ Pós-1988 } \\
\hline & & Anos $90^{1}$ & Anos $2000^{2}$ \\
\hline $\begin{array}{l}\text { - Competências } \\
\text { exclusivas e } \\
\text { definidas } \\
\text { - Grande centralização } \\
\text { financeira no GF } \\
\text { - Atenção à saúde, no } \\
\text { nível federal, feita } \\
\text { pelo sistema } \\
\text { previdenciário } \\
\text { - E e M possuem redes } \\
\text { próprias de atenção } \\
\text { à saúde, sem } \\
\text { comunicação entre si } \\
\text { - Forte mobilização dos } \\
\text { movimentos sociais } \\
\text { organizados na área } \\
\text { de saúde }\end{array}$ & $\begin{array}{l}\text { - Descentralização } \\
\text { - Competências } \\
\text { legislativas } \\
\text { concorrentes } \\
\text { - Competências comuns } \\
\text { a GF, E e M } \\
\text { - Sistema de saúde } \\
\text { hierárquico e unificado } \\
\text { (SUS) define a } \\
\text { cooperação federativa } \\
\text { - Participação da } \\
\text { sociedade em } \\
\text { conselhos } \\
\text { - Financiamento pelo } \\
\text { FPAS sob controle } \\
\text { federal }\end{array}$ & $\begin{array}{l}\text { - Política federal ativa de } \\
\text { descentralização } \\
\text { - Normas federais } \\
\text { definem os requisitos } \\
\text { para níveis diferentes } \\
\text { de administração } \\
\text { municipal e estadual do } \\
\text { SUS } \\
\text { - Normas federais } \\
\text { definem um novo } \\
\text { conceito de SUS } \\
\text { Municipal, baseado na } \\
\text { prevenção de doenças } \\
\text { e no controle } \\
\text { comunitário dos } \\
\text { serviços de saúde } \\
\text { - Normas federais para a } \\
\text { transferência } \\
\text { automática de recursos } \\
\text { aos municípios (PAB \& } \\
\text { MAC), em bases per } \\
\text { capita }\end{array}$ & $\begin{array}{l}\text { - Aprovação de NOAS, que } \\
\text { define, entre outras disposições, } \\
\text { a nível federal: transferência de } \\
\text { recursos segundo critérios } \\
\text { padronizados de execução de } \\
\text { programas; responsabilidades } \\
\text { mínimas e padrões para AB; } \\
\text { atualização dos critérios de } \\
\text { habilitação de E e M; } \\
\text { procedimentos para } \\
\text { atendimentos de média e alta } \\
\text { complexidade; protocolos de } \\
\text { assistência médica } \\
\text { - Indução à adesão por incentivo } \\
\text { financeiro (mediante termo de } \\
\text { compromisso) a programas com } \\
\text { prioridades definidas em âmbito } \\
\text { federal }\end{array}$ \\
\hline
\end{tabular}

${ }^{1}$ Fonte: Almeida (2000). ${ }^{2}$ Fonte: Portarias, NOBs e Leis referentes ao SUS. GF = Governo Federal; E = Estados; M = Municípios; SUS = Sistema Único de Saúde; FPAS = Fundo de Previdência, Assistência e Saúde; NOAS = Norma Operacional da Assistência à Saúde; AB = Atenção Básica

\section{Assistência Social}

\begin{tabular}{|c|c|c|c|}
\hline \multirow{2}{*}{ Antes de $1988^{1}$} & \multirow{2}{*}{ CF de $1988^{1}$} & \multicolumn{2}{|c|}{ Pós-1988 } \\
\hline & & Anos $1990^{1}$ & Anos $2000^{2}$ \\
\hline $\begin{array}{l}\text { - Competências } \\
\text { comuns } \\
\text { - Centralização } \\
\text { decisória e financeira } \\
\text { no GF } \\
\text { - E e M possuem } \\
\text { sistemas próprios } \\
\text { - Execução por meio } \\
\text { de organizações } \\
\text { assistenciais não } \\
\text { governamentais }\end{array}$ & $\begin{array}{l}\text { - Descentralização } \\
\text { - Competências } \\
\text { comuns } \\
\text { - GF define normas e } \\
\text { coordena ações. E, } \\
\text { M e organizações } \\
\text { assistenciais } \\
\text { executam programas } \\
\text { - Participação da } \\
\text { sociedade em } \\
\text { conselhos }\end{array}$ & $\begin{array}{l}\text { - Políticas federais ativas } \\
\text { de descentralização } \\
\text { - Lei federal (Lei Orgânica } \\
\text { da Assistência Social - } \\
\text { LOAS) define as } \\
\text { exigências para } \\
\text { transferência completa da } \\
\text { AS para os M e para a } \\
\text { transferência dos recursos }\end{array}$ & $\begin{array}{l}\text { - Aprovação da PNAS (2004) } \\
\text { - Criação do Sistema Único de } \\
\text { Assistência Social - SUAS } \\
\text { (2005): operacionalização da } \\
\text { LOAS, descentralização e } \\
\text { cofinanciamento com repasse } \\
\text { fundo a fundo mediante } \\
\text { condicionalidades } \\
\text { - Pisos de proteção social de } \\
\text { acordo com nivel de } \\
\text { complexidade dos programas, } \\
\text { projetos e serviços prestados } \\
\text { - Competências próprias para } \\
\text { cada ente: GF cria e regula } \\
\text { sistema, adesão voluntária de M, } \\
\text { DF e E } \\
\text { - NOB/SUAS (2012): } \\
\text { cofinanciamento federal dos } \\
\text { serviços, programas e projetos } \\
\text { pode ser realizado por Blocos de } \\
\text { Financiamento, gestão definida } \\
\text { pelo GF } \\
\text { - Responsabilidades comuns a U, } \\
\text { E e M; incentivos financeiros aos } \\
\text { M para apoio à gestão } \\
\text { descentralizada }\end{array}$ \\
\hline
\end{tabular}

${ }^{1}$ Fonte: Almeida (2000). ${ }^{2}$ CNM (2013). U = União; GF = Governo Federal; E = Estados; $M$ = Municípios; FPAS = Fundo de Previdência; AS = Assistência Social; PNAS = Política Nacional de AS; NOB = Norma Operacional Básica. 


\begin{tabular}{|c|c|c|c|}
\hline \multirow{2}{*}{ Antes de $1988^{1}$} & \multirow{2}{*}{ CF de $1988^{1}$} & \multicolumn{2}{|c|}{ Pós-1988 } \\
\hline & & Anos $1990^{1,2}$ & Anos $2000^{3}$ \\
\hline $\begin{array}{l}\text { - Centralização decisória e } \\
\text { financeira da U por meio } \\
\text { de agência federal (BNH) } \\
\text { - Extinção do BNH (1986), } \\
\text { a política passa por } \\
\text { diferentes ministérios até } \\
\text { os anos } 1990 \\
\text { - Descentralização da } \\
\text { implementação para } \\
\text { agentes promotores (E e } \\
\text { Me COHABs locais e } \\
\text { assemelhados) que } \\
\text { detinham alguma } \\
\text { autonomia na } \\
\text { implementação dos } \\
\text { programas } \\
\text { - Financiamento: FGTS }\end{array}$ & $\begin{array}{l}\text { - Estabeleceu } \\
\text { competência federal } \\
\text { exclusiva para definir } \\
\text { normas gerais } \\
\text { - Competências } \\
\text { comuns com estados e } \\
\text { municípios } \\
\text { - Não alterou o padrão } \\
\text { anteriormente } \\
\text { centralizado de } \\
\text { formulação e gestão } \\
\text { das políticas de } \\
\text { desenvolvimento } \\
\text { urbano } \\
\text { - Financiamento: FGTS }\end{array}$ & $\begin{array}{l}\text { - Forte redefinição das } \\
\text { funções do GF } \\
\text { - Programa federal de } \\
\text { transferência da } \\
\text { administração do FGTS } \\
\text { para conselhos estaduais. } \\
\text { - Em período de vazio da } \\
\text { política no nível federal, a } \\
\text { política passa por } \\
\text { diferentes órgãos do GF } \\
\text { - Iniciativas dispersas de } \\
\text { programas públicos de } \\
\text { habitação nos níveis } \\
\text { estadual e municipal }\end{array}$ & $\begin{array}{l}\text { - Criação da SNH (2003) } \\
\text { - Política Nacional de Habitação } \\
\text { (PNH) (2004) } \\
\text { - Sistema Nacional de Habitação } \\
\text { divide-se em: SNHM e SNHIS } \\
\text { - Lei Federal (2005) cria o SNHIS } \\
\text { e o FNHIS, com conselho gestor } \\
\text { - GF: coordenador, gestor e } \\
\text { formulador da PNH; E, DF e M: } \\
\text { órgãos descentralizados } \\
\text { - Financiamento: recursos } \\
\text { orçamentários e do FGTS } \\
\text { - Previsão de repasse de recursos } \\
\text { mediante o cumprimento de } \\
\text { condicionalidades } \\
\text { - Elaboração do PlanHab (2008), } \\
\text { sob coordenação do GF }\end{array}$ \\
\hline
\end{tabular}

${ }^{1}$ Fonte: Almeida (2000). ${ }^{2}$ Ärretche (1996).3 Lei de criação do SNHIS e FNHIS, Lei de criação do PlanHab

U = União; GF = Governo Federal; E = Estados; M = Municípios; FGTS = Fundo Garantidor de Tempo de Serviço; SNH = Secretaria

Nacional de Habitação; SNHM = Sistema Nacional de Habitação de Mercado; SNHIS = Sistema Nacional de Habitação de Interesse Social; Planhab = Plano Nacional de Habitação.

Saneamento

\begin{tabular}{|c|c|c|c|}
\hline \multirow{2}{*}{ Antes de $1988^{1}$} & \multirow{2}{*}{ CF de $1988^{1}$} & \multicolumn{2}{|c|}{ Pós-1988 } \\
\hline & & Anos $1990^{1}$ & Anos $2000^{2}$ \\
\hline $\begin{array}{l}\text { - Centralização decisória e } \\
\text { financeira no GF } \\
\text { (Planasa) } \\
\text { - Descentralização da } \\
\text { execução para } \\
\text { companhias estaduais } \\
\text { participantes do Planasa. } \\
\text { - Poucos municípios } \\
\text { operam sistemas } \\
\text { próprios }\end{array}$ & $\begin{array}{l}\text { - Competência federal } \\
\text { exclusiva para } \\
\text { definir normas } \\
\text { gerais do setor } \\
\text { - Competências } \\
\text { comuns de GF, E e } \\
\text { M para programas } \\
\text { de saneamento } \\
\text { básico - podem } \\
\text { estabelecer suas } \\
\text { próprias políticas e } \\
\text { tarifas. }\end{array}$ & $\begin{array}{l}\text { - Fim do Planasa - } \\
\text { inexistência de políticas } \\
\text { federais de } \\
\text { descentralização } \\
\text { - Inexistência de políticas } \\
\text { estaduais de } \\
\text { descentralização para os } \\
\text { municípios. } \\
\text { - GF não é titular } \\
\text { (competência comum), } \\
\text { mas define diretrizes } \\
\text { para prestação do } \\
\text { serviço e pode criar } \\
\text { política nacional, de } \\
\text { adesão voluntária com } \\
\text { incentivos para adesão } \\
\text { - Continua sendo } \\
\text { competência de M e E, } \\
\text { mas GF está criando } \\
\text { sistema nacional de livre } \\
\text { adesão dos E e M }\end{array}$ & $\begin{array}{l}\text { - Criação da SNSA (2003) } \\
\text { - Lei Federal (2007) estabelece } \\
\text { diretrizes nacionais para o } \\
\text { saneamento básico } \\
\text { - Nova Política Nacional do } \\
\text { Saneamento Ambiental (água, } \\
\text { esgoto, lixo e drenagem) e novo } \\
\text { marco regulatório estabelece as } \\
\text { diretrizes nacionais da política } \\
\text { - PNSA cria critérios de } \\
\text { delegação: GF estabelece } \\
\text { critérios para tarifação; indução } \\
\text { para criação de consórcios } \\
\text { regionais; M e E que aderirem } \\
\text { devem criar planos de } \\
\text { saneamento; cria conselhos } \\
\text { para controle social } \\
\text { - Integração no âmbito do GF das } \\
\text { ações na área do saneamento } \\
\text { - Elaboração do Plansab (2011) } \\
\text { sob coordenação do GF }\end{array}$ \\
\hline
\end{tabular}

${ }^{1}$ Fonte: Almeida (2000). ${ }^{2}$ Lei de criação do SNSA, Lei de Criação do Plansab

GF = Governo Federal; E = Estados; M = Municípios; FGTS = Fundo Garantidor de Tempo de Serviço; SNSA = Secretaria Nacional de Saneamento Ambiental; Plansab = Plano Nacional de Saneamento Básico. 
Gabriela Spanghero Lotta - Renata Gonçalves - Marina Bitelman

\section{Cultura}

\begin{tabular}{|c|c|c|c|}
\hline \multirow{2}{*}{ Antes de $1988^{1}$} & \multirow{2}{*}{ CF de $1988^{1}$} & \multicolumn{2}{|c|}{ Pós-1988 } \\
\hline & & Anos $1990^{1}$ & Anos $2000^{2}$ \\
\hline $\begin{array}{l}\text { - Destaque para órgãos } \\
\text { federais, como IPHAN } \\
\text { e Funarte } \\
\text { - Cultura era vinculada } \\
\text { ao Ministério da } \\
\text { Educação } \\
\text { - Em 1985, criação do } \\
\text { Ministério da Cultura }\end{array}$ & $\begin{array}{l}\text { - Competências comuns } \\
\text { a União, E e M } \\
\text { - Competências } \\
\text { concorrentes na } \\
\text { conservação do } \\
\text { patrimônio cultural, } \\
\text { artístico e histórico }\end{array}$ & $\begin{array}{l}\text { - Leis federais } \\
\text { normatizando o } \\
\text { incentivo à Cultura } \\
\text { (como Lei Rouanet, } \\
\text { Lei do Audiovisual) }\end{array}$ & $\begin{array}{l}\text { - EC (2005) prevê a elaboração } \\
\text { do Plano Nacional de Cultura } \\
\text { (PNC) } \\
\text { - Decreto Federal (2005) } \\
\text { dispõe sobre o Conselho } \\
\text { Nacional de Política Cultural, } \\
\text { instalado em dez./2007. } \\
\text { - Lei Federal (2010) aprova o } \\
\text { PNC e cria o Sistema } \\
\text { Nacional de Informações e } \\
\text { Indicadores Culturais (SNIIC) } \\
\text { - EC (2012) institui o Sistema } \\
\text { Nacional de Cultura, } \\
\text { organizado em regime de } \\
\text { colaboração e de forma } \\
\text { descentralizada e participativa } \\
\text { - Fundo Nacional de Cultura, } \\
\text { por meio de seus fundos } \\
\text { setoriais, previsto como } \\
\text { principal mecanismo de } \\
\text { fomento às políticas culturais }\end{array}$ \\
\hline
\end{tabular}

${ }^{1}$ Fonte: Almeida (2000). ${ }^{2}$ Lei de criação do Sistema Nacional de Cultura, Lei de Criação do Plano Nacional de Cultura. GF = Governo Federal; $\mathrm{E}=$ Estados; $\mathrm{M}$ = Municípios; EC = Emenda Constitucional.

\section{Segurança Pública}

\begin{tabular}{|c|c|c|c|}
\hline \multirow{2}{*}{ Antes de $1988^{1}$} & \multirow{2}{*}{ CF de $1988^{1}$} & \multicolumn{2}{|c|}{ Pós-1988 } \\
\hline & & Anos $1990^{1}$ & Anos $2000^{2}$ \\
\hline $\begin{array}{l}\text { - Polícias federal, } \\
\text { militar e civil, com } \\
\text { atribuições } \\
\text { específicas }\end{array}$ & $\begin{array}{l}\text { - Trouxe } \\
\text { competências aos } \\
\text { municípios - } \\
\text { guardas municipais }\end{array}$ & $\begin{array}{l}\text { - Secretaria Nacional de } \\
\text { Segurança Pública criada } \\
\text { em } 1998\end{array}$ & $\begin{array}{l}\text { - PL (2007) disciplina a } \\
\text { organização e o } \\
\text { funcionamento dos órgãos } \\
\text { responsáveis pela SP, institui } \\
\text { o Sistema Único de } \\
\text { Segurança Pública (SUSP), } \\
\text { dispõe sobre a Segurança } \\
\text { Cidadã } \\
\text { - Pronasci - programa federal } \\
\text { articula programas de SP } \\
\text { com políticas sociais já } \\
\text { desenvolvidas pelo GF } \\
\text { - GF regulamenta, fiscaliza, } \\
\text { aporta recursos } \\
\text { - E e M (além de ONGs) } \\
\text { firmam convênios com GF } \\
\text { para implementar ações } \\
\text { - E e M devem criar GGI e } \\
\text { gerenciam as ações } \\
\text { - Institucionalização de } \\
\text { espaços de participação } \\
\text { social }\end{array}$ \\
\hline
\end{tabular}

${ }^{1}$ Fonte: Almeida (2000). ${ }^{2}$ Lei de criação do Pronasci, Proposta de criação do SUSP

GF = Governo Federal; E = Estados; M = Municípios; SP = Segurança Pública; GGI = Gabinete de Gestão Integrada; PL = Projeto de Lei. 


\begin{tabular}{|c|c|c|c|}
\hline \multirow{2}{*}{ Antes de $1988^{1}$} & \multirow{2}{*}{ CF de $1988^{1}$} & \multicolumn{2}{|c|}{ Pós-1988 } \\
\hline & & Anos $1990^{1}$ & Anos 2000 \\
\hline $\begin{array}{l}\text { - Sistema estadual } \\
\text { - Início da } \\
\text { centralização com o } \\
\text { IBAMA } \\
\text { - Criação do Sisnama } \\
\quad(1981)\end{array}$ & $\begin{array}{l}\text { - Competências } \\
\text { legislativas } \\
\text { concorrentes } \\
\text { - Competências } \\
\text { comuns }\end{array}$ & $\begin{array}{l}\text { - Tendência à centralização } \\
\text { com criação do Ministério } \\
\text { do Meio Ambiente } \\
\text { - Regulamentação do } \\
\text { Sisnama (Decreto n. } \\
\text { 9.9274/90). } \\
\text { - Programa Nacional de } \\
\text { Meio Ambiente (1991) } \\
\text { - Política de } \\
\text { descentralização } \\
\text { impulsionada pela Eco92. } \\
\text { - Criação de fundos } \\
\text { estaduais para apoiar } \\
\text { projetos municipais }\end{array}$ & $\begin{array}{l}\text { - Programa Nacional de Meio } \\
\text { Ambiente, etapa I (2000) e II } \\
\text { (2005) para colocar em prática } \\
\text { o Sisnama, descentralizar } \\
\text { ações e incentivar estados e } \\
\text { municípios a aderir a } \\
\text { programas federais } \\
\text { - Institucionalização de espaços } \\
\text { de planejamento e } \\
\text { participação social, como a I e } \\
\text { II Conferência Nacional de } \\
\text { Meio Ambiente (2003 e 2005) } \\
\text { - Implementação das } \\
\text { Comissões Técnicas } \\
\text { Tripartites Estaduais (2003), } \\
\text { espaços de diálogo entre } \\
\text { órgãos e entidades ambientais } \\
\text { dos M, E, DF e GF }\end{array}$ \\
\hline
\end{tabular}

1 Fonte: Almeida (2000). GF = Governo Federal; E = Estados; M = Municípios; Sisnama = Sistema Nacional do Meio Ambiente.

\section{Educação}

\begin{tabular}{|c|c|c|c|}
\hline \multirow{2}{*}{ Antes de $1988^{1}$} & \multirow{2}{*}{ CF de $1988^{1}$} & \multicolumn{2}{|c|}{ Pós-1988 } \\
\hline & & Anos $1990^{1}$ & Anos $2000^{2}$ \\
\hline $\begin{array}{l}\text { - Competências eram } \\
\text { comuns aos três níveis } \\
\text { de governo, que } \\
\text { assumiam funções de } \\
\text { maneira aleatória: GF: } \\
\text { universidades, material } \\
\text { didático e merenda } \\
\text { escolar; E: educação } \\
\text { básica, secundária e } \\
\text { universidades, M: El }\end{array}$ & $\begin{array}{l}\text { - Competências } \\
\text { legislativas } \\
\text { concorrentes } \\
\text { - Algumas } \\
\text { competências comuns } \\
\text { com priorização para: } \\
\text { GF: ES e } \\
\text { regulamentação da } \\
\text { educação do país; E: } \\
\text { EM e EF (dependendo } \\
\text { da capacidade dos M); } \\
\text { M: El e EF } \\
\text { - Processo de } \\
\text { descentralização da } \\
\text { merenda escolar e } \\
\text { material didático } \\
\text { - Financiamento: } \\
\text { vinculação } \\
\text { orçamentária: } 18 \% \text { do } \\
\text { GF, 25\% dos E e M e } \\
\text { contribuição } \\
\text { compulsória das } \\
\text { empresas }\end{array}$ & $\begin{array}{l}\text { - Políticas federais de } \\
\text { descentralização da } \\
\text { merenda escolar e de } \\
\text { livros didáticos para os M } \\
\text { — Lei federal determina } \\
\text { recursos casados do GF } \\
\text { e dos M em bases per } \\
\text { capita (Fundef) } \\
\text { _ Inexistência de políticas } \\
\text { de transferência da } \\
\text { educação básica dos E } \\
\text { para os M com } \\
\text { abrangência nacional } \\
\text { - Iniciativas de } \\
\text { descentralização variam } \\
\text { de estado a estado } \\
\text { - Algumas iniciativas para } \\
\text { aumentar a autonomia } \\
\text { administrativa e } \\
\text { financeira das escolas }\end{array}$ & $\begin{array}{l}\text { - Plano Nacional de } \\
\text { Educação. } \\
\text { — Fundeb: Criado pela EC } \\
\text { n. 53/06, } \\
\text { regulamentado pela } \\
\text { MP 339/06, convertida } \\
\text { na Lei n. 11.494/07. } \\
\text { Segue modelo do } \\
\text { Fundef, com recursos } \\
\text { dos três níveis: } 18 \% \text { do } \\
\text { orçamento do GF e } \\
25 \% \text { do orçamento dos } \\
\text { E e M } \\
\text { - GF determina padrões } \\
\text { e regulamenta } \\
\text { - E e M implementam a } \\
\text { educação básica, que } \\
\text { inclui: El; EF; EM } \\
\text { (técnico ou não); EJA }\end{array}$ \\
\hline
\end{tabular}

${ }^{1}$ Fonte: Almeida (2000). ${ }^{3}$ Lei de criação do Fundeb. GF = Governo Federal; E = Estados; M = Municípios; ES = Ensino Superior; EM = Ensino Médio; EF = Ensino Fundamental; EI = Ensino Infantil; EJA = Educação de Jovens e Adultos. 
Gabriela Spanghero Lotta - Renata Gonçalves - Marina Bitelman

\section{Combate à pobreza}

\begin{tabular}{|c|c|c|c|}
\hline \multirow{2}{*}{ Antes de 1988 } & \multirow{2}{*}{ CF de 1988 } & \multicolumn{2}{|c|}{ Pós-1988 } \\
\cline { 2 - 4 } & & \multicolumn{1}{|c|}{ Anos 1990 } & Anos 2000 \\
\hline - Não havia uma & - Cria competências & - Programa federal & - Integração dos programas federais \\
área de política & comuns para o & Comunidade Solidária & (2003) com dois eixos \\
específica & combate à pobreza & coordena ação de & Segão: Programa de \\
- Fragmentação de & & diferentes agências & Segurança Alimentar (Fome Zero) e \\
programas federais & & federais nos municípios & Combate à pobreza (Programa \\
nos Ministérios de & & mais pobres atuando & Bolsa Família) \\
Saúde, Educação, & junto com administrações & - Manutenção do controle federal \\
Assistência Social & & locais, ONGs e empresas & sobre a política \\
e Agricultura. & - Programa Bolsa Escola & \\
- Alguns E e M com & & - Experiências locais de & \\
programas & programas de renda & \\
próprios & mínima & \\
\hline
\end{tabular}

1 Fonte: Almeida (2000).3 Normas do Programa Bolsa Família e do Fome Zero

GF = Governo Federal; E = Estados; $M=$ Municípios

A seguir, apresenta-se um quadro geral com uma síntese comparativa do panorama recente das políticas, organizado a partir de algumas categorias de análise. 
A Coordenação Federativa de Políticas Públicas: uma análise das políticas brasileiras nas últimas décadas

Quadro com o panorama das políticas públicas em 2010

\begin{tabular}{|c|c|c|c|c|c|c|c|c|}
\hline Area & Saúde & Assistência Social & Habitação & Meio Ambiente & Cultura & $\begin{array}{l}\text { Segurança } \\
\text { Pưblica }\end{array}$ & Saneamento & Educaçäo \\
\hline $\begin{array}{l}\text { Competências } \\
\text { constitucionais }\end{array}$ & $\begin{array}{l}\text { Competências } \\
\text { legislativas } \\
\text { concorrentes } \\
\text { - Competências } \\
\text { comuns }\end{array}$ & $\begin{array}{l}\text { Competências } \\
\text { comuns } \\
\text { - GF: define nomars } \\
\text { e coordena açóes } \\
\text {-E, Me } \\
\text { organizacōos } \\
\text { assistenciais } \\
\text { executam } \\
\text { programas }\end{array}$ & $\begin{array}{l}\text { Competéncia } \\
\text { federal exciusiva } \\
\text { para definir } \\
\text { normas gerais } \\
\text { - Competências } \\
\text { comuns }\end{array}$ & $\begin{array}{l}\text { - Competências } \\
\text { legislativas } \\
\text { concorrentes } \\
\text { - Competências } \\
\text { comuns }\end{array}$ & $\begin{array}{l}\text { Competências } \\
\text { comuns a U. E e } \\
\text { M Competências } \\
\text { - Comcorrentes na } \\
\text { conconservacão do } \\
\text { património do } \\
\text { culturá, artistico } \\
\text { e histórico }\end{array}$ & $\begin{array}{l}\text { Divide as } \\
\text { competências } \\
\text { para cada } \\
\text { organização da } \\
\text { segurança pública } \\
\text { (policias e. } \\
\text { bombero. } \\
\text { vinculadas ao GF } \\
\text { eaos E } \\
\text { M: guardas } \\
\text { municipais }\end{array}$ & $\begin{array}{l}\text { Competência } \\
\text { federal exclusiva } \\
\text { para definir } \\
\text { normas gerais do } \\
\text { setor } \\
\text { - Competências } \\
\text { comuns de GF. } \\
\text { E e M para } \\
\text { programas - } \\
\text { poderm } \\
\text { estabelecer } \\
\text { suas próprias } \\
\text { politicase } \\
\text { tarifas }\end{array}$ & $\begin{array}{l}\text { - Competências } \\
\text { legislativas } \\
\text { concorrentes } \\
\text { - Algumas } \\
\text { competéncias } \\
\text { comuns com } \\
\text { priorização para: GF: } \\
\text { ESe } \\
\text { regulamentaacão da } \\
\text { educacão do pais; E: } \\
\text { EM e EF } \\
\text { (dependendo da } \\
\text { capacidade dos M): } \\
\text { M: El e EF }\end{array}$ \\
\hline $\begin{array}{l}\text { Formato } \\
\text { institucional }\end{array}$ & sus & SUAS & SNHIS & $\begin{array}{l}\text { Sisnama/ PNMA } \\
\text { III }\end{array}$ & SNC. PNC & $\begin{array}{l}\text { SUSP (ainda em } \\
\text { votaçaio) } \\
\text { Pronasci }\end{array}$ & $\begin{array}{l}\text { Política Federal } \\
\text { de Saneamento } \\
\text { Básico }\end{array}$ & $\begin{array}{l}\text { PNE/ Fundef/ } \\
\text { Fundeb }\end{array}$ \\
\hline $\begin{array}{l}\text { Competências } \\
\text { Formulação }\end{array}$ & $\begin{array}{l}\text { GF: formula diretrizes, } \\
\text { padróes de } \\
\text { funcionamento. } \\
\text { programas. } \\
\text { responsabilidades } \\
\text { minimas, } \\
\text { procedimentos de } \\
\text { atenģäo médica e } \\
\text { protocolos de } \\
\text { assisténcia } \\
\text { E e M: desenvolvem } \\
\text { planos com base na } \\
\text { adesäo a programas }\end{array}$ & $\begin{array}{l}\text { GF: formula } \\
\text { diretrizes, padrões de } \\
\text { funcionamento, } \\
\text { programas. } \\
\text { responsabiidades } \\
\text { minimas, } \\
\text { procedimentos de } \\
\text { atençäo e protocolos } \\
\text { de assistência } \\
\text { E e M: desenvolvem } \\
\text { planos com base na } \\
\text { adesäo a programas } \\
\text { e padröes federais }\end{array}$ & $\begin{array}{l}\text { GF: responsável } \\
\text { pelas diretrizes, } \\
\text { prioridades, } \\
\text { estratégias e } \\
\text { instrumentos da } \\
\text { PNH, coordena o } \\
\text { SNH } \\
\text { E e M: participam } \\
\text { de seleçóes para } \\
\text { os programas } \\
\text { federais, } \\
\text { criam conselhos, } \\
\text { fundos e planos }\end{array}$ & $\begin{array}{l}\text { GF: regulamenta } \\
\text { nommase } \\
\text { padrón, via } \\
\text { atuaçäo do } \\
\text { Conama } \\
\text { E e M: elaboram } \\
\text { nomas com base } \\
\text { nas estabelecidas } \\
\text { pelo GF }\end{array}$ & $\begin{array}{l}\text { GF: formula, } \\
\text { promove e, } \\
\text { executa politicas, } \\
\text { programas e } \\
\text { apoes } \\
\text { Ee M M aderem a } \\
\text { eles e } \\
\text { implementam } \\
\text { estrutura minima } \\
\text { exigida e açoes } \\
\text { Coresponsabilidad } \\
\text { ede diferentes } \\
\text { instâncias do }\end{array}$ & $\begin{array}{l}\text { GF: firma } \\
\text { corvénios com E } \\
\text { e Me ONGs para } \\
\text { implementar ass } 24 \\
\text { acoes previstas } \\
\text { Coordiena no nivel } \\
\text { federal por meio } \\
\text { de secretaria- } \\
\text { executiva }\end{array}$ & $\begin{array}{l}\text { GF: estabelece } \\
\text { diretrizes } \\
\text { nacionais para o } \\
\text { saneamento } \\
\text { básico } \\
\text { O titular dos } \\
\text { serviços formula a } \\
\text { respectiva política } \\
\text { Ao aderir a ela, } \\
\text { deve criar planos } \\
\text { econselhos, entre } \\
\text { outras exigéncias }\end{array}$ & $\begin{array}{l}\text { GF: determina e } \\
\text { regulamenta padrôes a } \\
\text { serem seguidos (LDB) } \\
\text { e elabora o PNE } \\
\text { OCNE, ligado ao } \\
\text { MEC, regulamenta. } \\
\text { nomatiza, delibera e é } \\
\text { consultivo } \\
\text { E e M: podem awançar } \\
\text { alem dos mínimos } \\
\text { exigidos }\end{array}$ \\
\hline
\end{tabular}

\begin{tabular}{|c|c|c|c|c|c|c|c|c|}
\hline Área & Saúde & Assistência Social & Habitação & Meio Ambiente & Cultura & $\begin{array}{l}\text { Segurança } \\
\text { Pública }\end{array}$ & Saneamento & Educaçäo \\
\hline & e padrōes federais & & locais & & $\begin{array}{l}\text { poder público e da } \\
\text { sociedade }\end{array}$ & & & \\
\hline Implementação & $\begin{array}{l}\text { E: responsável pela } \\
\text { saúde terciáaria eparte } \\
\text { da secundária, pelo } \\
\text { desenvimento } \\
\text { tecnológico, dá } \\
\text { assisténcia aos } \mathrm{M} \text {, } \\
\text { estabelece CIB e } \\
\text { conselho estadual, } \\
\text { repassa recursos } \\
\text { M: adere a } \\
\text { programas, } \\
\text { responsável pela } \\
\text { saude primária e } \\
\text { parte da secundária } \\
\text { coordena açóes. } \\
\text { repassa recursos, cria } \\
\text { conselho local, } \\
\text { alimenta sistema de } \\
\text { informacóes }\end{array}$ & $\begin{array}{l}\text { E: coordena politica } \\
\text { estadual, acompanha } \\
\text { M, estabelece ClB e } \\
\text { conselho estadual, } \\
\text { repassa recursos } \\
\text { para M, dá apoio } \\
\text { técnico e incentiva } \\
\text { criação de consórcios } \\
\text { intermunicipais } \\
\text { M: adere a } \\
\text { programas, coordena } \\
\text { açes, alimenta } \\
\text { sistema de } \\
\text { informaçăo, repassa } \\
\text { recursos, cria } \\
\text { conselho local }\end{array}$ & $\begin{array}{l}\text { GF: oferece } \\
\text { suporte técnico } \\
\text { para E e M } \\
\text { E: implementam } \\
\text { programas } \\
\text { devern ser } \\
\text { articuladores das } \\
\text { aços do setor } \\
\text { habitacional no } \\
\text { ternitónio } \\
\text { M: implementam } \\
\text { programas }\end{array}$ & $\begin{array}{l}\text { GF e E: fazem } \\
\text { licenciamento } \\
\text { ambiental de } \\
\text { empreendimento } \\
\text { e atividades de } \\
\text { impacto } \\
\text { M: exerce } \\
\text { vigilancia, faz } \\
\text { licenciamento } \\
\text { ambiental de } \\
\text { empreendimento } \\
\text { e atvidades de } \\
\text { impacto local. } \\
\text { após ouvir órgãos } \\
\text { competentes da } \\
\text { Ue E, e criam } \\
\text { conselhos locais } \\
\text { de meio ambiente }\end{array}$ & $\begin{array}{l}\text { Prevê } \\
\text { implementação } \\
\text { descentralizada } \\
\text { dos programas } \\
\text { para E E M e } \\
\text { ONGs (E E M } \\
\text { implementam as } \\
\text { açoes) }\end{array}$ & $\begin{array}{l}\text { GF: elabora as } \\
\text { acóes vinculadas } \\
\text { ao Pronascia } \\
\text { repassa recursos } \\
\text { Ee M: } \\
\text { apresentam } \\
\text { projetos de } \\
\text { implementação } \\
\text { das acóes ja } \\
\text { desenhadas pelo } \\
\text { GF } \\
\text { Devem criar } \\
\text { Gabinete de } \\
\text { Gestäo Integra } \\
\text { que gerenciam as } \\
\text { acóes no plano } \\
\text { local }\end{array}$ & $\begin{array}{l}\text { Titulares dos } \\
\text { serviços públicos } \\
\text { de saneamento } \\
\text { básico podem } \\
\text { delegar } \\
\text { organização. } \\
\text { regulaçäo, } \\
\text { fiscalizaçäo e } \\
\text { prestaçaso dos } \\
\text { serviços } \\
\text { Prevé prestação } \\
\text { regionalizada }\end{array}$ & $\begin{array}{l}\text { E: implementa o EF e } \\
\text { EM, pricoritariamente } \\
\text { Ensino Superior de } \\
\text { competência } \\
\text { compartilhada com GF } \\
\text { M: implementa o EFe } \\
\text { a El }\end{array}$ \\
\hline $\begin{array}{l}\text { Financiaml } \\
\text { Forma de } \\
\text { repasse }\end{array}$ & $\begin{array}{l}\text { Transferência de } \\
\text { fundo a fundo com } \\
\text { critérios per capita,a, } \\
\text { segundo critérios } \\
\text { padronizados por } \\
\text { programase } \\
\text { definiçóes de } \\
\text { programas } \\
\text { intermunicipais } \\
\text { - Alcance dos } \\
\text { padróes ea } \\
\text { alimentação dos } \\
\text { sistentas de }\end{array}$ & $\begin{array}{l}\text { Criação de fundo } \\
\text { com repasse do GF a } \\
\text { partir de critérios: } \\
\text { indice de } \\
\text { vulnerabilidade, } \\
\text { adesäo a programas } \\
\text { e cumprimento dos } \\
\text { padröes } \\
\text { estabelecidos }\end{array}$ & $\begin{array}{l}\text { OGU e FGTS } \\
\text { Previsajo de } \\
\text { transferencia } \\
\text { fundo a fundo para } \\
\text { HIS } \\
\text { Constituiçäo do } \\
\text { FNHIS }\end{array}$ & $\begin{array}{l}\text { Federal ou } \\
\text { descentralizado, } \\
\text { mas sem } \\
\text { articulação }\end{array}$ & $\begin{array}{l}\text { Próprio e } \\
\text { autonomo para } \\
\text { cada ente } \\
\text { preferencialmente } \\
\text { aos fundos de } \\
\text { cultura } \\
\text { constituidos }\end{array}$ & $\begin{array}{l}\text { Por meio de } \\
\text { convenios, } \\
\text { contratos, acordos } \\
\text { e consórcios com } \\
\text { E, M, ONGs e } \\
\text { organismos } \\
\text { internacionais }\end{array}$ & $\begin{array}{l}\text { GF, E e M podem, } \\
\text { isoladamente ou } \\
\text { em consórcios } \\
\text { publicar, instituir } \\
\text { fundos, cujos } \\
\text { recursos podem } \\
\text { ser usados como } \\
\text { fontes ou } \\
\text { garantias em } \\
\text { operacóes de } \\
\text { credito para } \\
\text { financiam dos } \\
\text { investimentos }\end{array}$ & $\begin{array}{l}\text { Transferência de fundo } \\
\text { a fundo Fundeb: } \\
\text { somam-se, no âmbito } \\
\text { dos E e DF, a receita } \\
\text { de impostos e a } \\
\text { transferéncia } \\
\text { subvinculada, } \\
\text { distribuindo-a em } \\
\text { razáo do n. de } \\
\text { matriculas - onde o } \\
\text { valor médio não } \\
\text { alcançar o mínimo } \\
\text { definido }\end{array}$ \\
\hline
\end{tabular}

\begin{tabular}{|c|c|c|c|c|c|c|c|c|}
\hline Area & Saúde & Assistência Social & Habitação & Meio Ambiente & Cultura & $\begin{array}{l}\text { Segurança } \\
\text { Pública }\end{array}$ & Saneamento & Educaçäo \\
\hline & $\begin{array}{l}\text { monitoramento (por } \\
\text { E e M) está } \\
\text { vinculada ao } \\
\text { recebimento dos } \\
\text { repasses de } \\
\text { recursos }\end{array}$ & & & & & & & $\begin{array}{l}\text { nacionalmente, o } \\
\text { Fundeb será } \\
\text { complementado pela } \\
\text { Uniáo }\end{array}$ \\
\hline Normatizaçäo & NOBs e NOAS & LOAS E NOBs & $\begin{array}{l}\text { Leis federais e } \\
\text { Portarias } \\
\text { Ministeriais }\end{array}$ & $\begin{array}{l}\text { Lei (Sisnama) e } \\
\text { decretos } \\
\text { regulamentados }\end{array}$ & $\begin{array}{l}\text { Emenda } \\
\text { Constitucional e } \\
\text { Lei Federal }\end{array}$ & $\begin{array}{l}\text { Pronasci: criado } \\
\text { por lei federal }\end{array}$ & Lei Federal (2007) & $\begin{array}{l}\text { Emenda } \\
\text { Constitucional. MP e } \\
\text { Lei Federal }\end{array}$ \\
\hline Adesão & Voluntária & Voluntária & Voluntária & $\begin{array}{l}\text { Me E tềm } \\
\text { competéncias } \\
\text { obrigatónias }\end{array}$ & Voluntária & Voluntária & Voluntária & Compulsória \\
\hline Vinculaçäo* & $\begin{array}{l}\text { Mínimos de Repasse } \\
\text { GF: } 11.5 \%: \mathrm{E}: 12 \% \\
\text { M: } 15 \% \text { da } \\
\text { arrecadacãa + } \\
\text { transferências }\end{array}$ & Não há & Nä̀ há & Não há & Năo há & Nẫ há & Nä̀ há & $\begin{array}{l}\text { E e M: vinculaçấ de } \\
25 \% \text { da receita; GF: } \\
18 \% \text {. Destes recursos. } \\
60 \% \text { devem ser } \\
\text { imvestidos no Fundeb }\end{array}$ \\
\hline $\begin{array}{l}\text { Sistema de } \\
\text { monitoramento } \\
\text { e avaliação }\end{array}$ & $\begin{array}{l}\text { GF cria padrôes de } \\
\text { avaliaçáo para } \\
\text { programas. } \\
\text { gerenciamento de } \\
\text { diversos sistermas de } \\
\text { monitoramento } \\
\text { ligados às politicas }\end{array}$ & $\begin{array}{l}\text { GF cria paciónes de } \\
\text { avaliaçáo para } \\
\text { programas. } \\
\text { gerenciamento de } \\
\text { diversos sintemas de } \\
\text { monitoramento de } \\
\text { ligados às politicas }\end{array}$ & Nä̀ há & Não há & $\begin{array}{l}\text { Preve Sistema } \\
\text { Nacional de } \\
\text { Informacóes } \\
\text { Culturais. } \\
\text { coordenado pelo } \\
\text { GF e alimentado } \\
\text { por M que } \\
\text { aderirem ao SNC }\end{array}$ & $\begin{array}{l}\text { Para SUSP } \\
\text { previsấo da } \\
\text { construçäo de um } \\
\text { sistemade } \\
\text { informaçóes para } \\
\text { monitoramento }\end{array}$ & 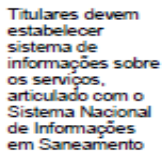 & $\begin{array}{l}\text { Sistema de Avaliação } \\
\text { da Educaçâa Básica } \\
\text { (SAEBE), composto pela } \\
\text { (ANEB) e } \\
\text { (ANRESCIProva } \\
\text { Brasil) }\end{array}$ \\
\hline $\begin{array}{l}\text { Tipos de gestäo } \\
\text { dos entes } \\
\text { subnacionais }\end{array}$ & $\begin{array}{l}\text { Gestão Plena e } \\
\text { Básica }\end{array}$ & $\begin{array}{l}\text { Gestão Inicial. Básica } \\
\text { e Plena }\end{array}$ & Nä̀o há & Não há & Năo há & Não há & Nä̀ há & Năo há \\
\hline
\end{tabular}

GF: Governo Federal; E: Estados; M: Municípios. *As receitas vinculadas são os recursos orçamentários que têm destinação especificada em lei. Os recursos são transferidos automaticamente para os entes subnacionais. 


\section{Considerações finais}

Dado que expressivas desigualdades e heterogeneidades regionais caracterizam o Estado federativo brasileiro e, ainda, que mais de uma esfera de governo atua sobre um mesmo território e população, é de fundamental importância 0 debate a respeito da coordenação de políticas. Coordenação, que, por parte do governo federal, envolve, além da articulação entre diferentes níveis de governo, os mecanismos de incentivos e indução, as normatizações, os bons desenhos de programas, a redefinição da atribuição de responsabilidades e competências, as transferências de recursos e a organização e capacitação de quadros técnicos (tanto do órgão coordenador quanto dos órgãos de quem está na ponta da implementação), entre outros aspectos.
Analisando-se, ainda que de maneira sintética, as nove políticas públicas, verificouse que, no atual contexto federativo brasileiro, caminha-se para um claro movimento geral de coordenação federal, o qual se expressa na criação de sistemas, planos ou programas nacionais com incentivos à adesão dos entes subnacionais, combinada à exigência de contrapartidas a serem cumpridas por parte desses entes, como a institucionalização de conselhos e fundos, por exemplo, e o atendimento a padrões de execução das políticas. Nos anos 2000, as políticas apresentam em comum a lógica da transferência de recursos, muitas vezes fundo a fundo (ao menos em sua concepção), da regulamentação federal de padrões e definição de competências, da adesão voluntária e da previsão de sistemas de informação e de monitoramento e avaliação que permitem coordenação federal.

Quadro síntese da coordenação das políticas no contexto federativo dos anos 2000

\begin{tabular}{|l|l|}
\hline Saúde & Coordenação federal por meio do Sistema Único de Saúde \\
\hline Assistência Social & Coordenação federal por meio do Sistema Único de Assistência Social \\
\hline Combate à Pobreza & $\begin{array}{l}\text { Programas federais implementados com adesão dos entes subnacionais e } \\
\text { coordenação do governo federal }\end{array}$ \\
\hline Habitação & Coordenação federal por meio do Sistema Nacional de Habitação de Interesse Social \\
\hline Saneamento & $\begin{array}{l}\text { Movimento de coordenação federal por meio da Política Nacional do Saneamento } \\
\text { Ambiental }\end{array}$ \\
\hline Meio Ambiente & Movimento de coordenação federal por meio do PNMA II \\
\hline Cultura & $\begin{array}{l}\text { Movimento de coordenação federal por meio do Sistema Nacional de Cultura (em } \\
\text { construção) }\end{array}$ \\
\hline Segurança Pública & $\begin{array}{l}\text { Movimento de coordenação federal por meio da criação do SUSP e da organização da } \\
\text { primeira Conferência Nacional de Segurança Pública (Conseg) }\end{array}$ \\
\hline Educação & $\begin{array}{l}\text { Coordenação federal por meio do Plano Nacional de Educação e da aprovação do } \\
\text { Fundef e Fundeb }\end{array}$ \\
\hline
\end{tabular}

Esses movimentos corroboram as evidências encontradas por Arretche (2012) a respeito do movimento de fortalecimento do governo federal como normatizador e financiador enquanto estados e municípios aparecem como executores das políticas. Esse movimento tem ao menos duas consequências: se, por um lado, enfraquece municípios e estados no âmbito da federação, por outro gera maior homogeneidade em termos de investimentos e políticas a serem realizadas por todos os entes federativos, como argumenta parte da literatura.

Nesse sentido, é possível perceber arranjos que, embora dêem caráter normatizador ao governo federal, criam instâncias específicas e institucionalizadas para negociação entre os vários entes 
federativos - como é o caso do SUS e do SUAS.

Outra consideração importante que se pode extrair das evidências apresentadas é a respeito do papel destinado aos estados no arranjo federativo brasileiro. Boa parte da literatura argumenta o enfraquecimento dos governos estaduais no desenho apontado pela Constituição. $O$ que se percebe nos esboços dos arranjos apresentados é que, na maioria das vezes, os governos estaduais aparecem como apenas mais um ente federativo, em graus similares aos dos municípios, com poucas responsabilidades diferenciadas, inclusive em termos de coordenação de municípios. Essa evidência, que merece ser mais bem explorada, parece corroborar o que parte da literatura sinaliza e demonstra que há um enfraquecimento ou indefinição do papel dos estados nesses sistemas e programas nacionais construídos.

Destaca-se, ainda, a partir dos anos 2000, o aumento significativo da incorporação de processos e instâncias participativas no âmbito das políticas, que se traduzem na realização de conferências nacionais organizadas pelo governo federal, bem como na criação de conselhos nacionais das políticas e conselhos gestores de fundos setoriais, ambos com previsão similar no âmbito das esferas subnacionais.

É interessante destacar também que
alguns sistemas e programas apontam, ao menos em temos normativos, para uma tendência à integração entre políticas de diferentes áreas, contribuindo-se para o rompimento de padrões de excessiva fragmentação setorial.

Pode-se considerar que esse movimento de coordenação expressa, de certo modo, um fortalecimento do papel do governo central na coordenação de políticas o que, entretanto, não significa necessariamente uma tendência homogeneizadora das políticas no território, ao menos em termos dos desenhos construídos. Embora se esteja observando, em comum entre as políticas, a constituição de sistemas, planos e programas nacionais com a coordenação federal, eles também resultam das especificidades, naturezas e legados históricos de cada uma das políticas, assim como das distintas capacidades dos entes subnacionais nas diferentes áreas setoriais.

As políticas analisadas carregam distintos legados e desenvolvimentos institucionais, inserem-se em diferentes arenas e envolvem atores e coalizões que variamentreas políticas eao longo do tempo, colocando ainda uma série de desafios que demandam estudos específicos mais aprofundados. O panorama geral do quadro das políticas públicas, no Brasil na primeira década dos anos 2000 , revela uma tendência convergente entre as políticas no sentido da coordenação por parte do governo federal, indicando novos padrões de relações intergovernamentais no contexto federativo brasileiro.

Contudo, ao final da década, já é possível identificar os rumos que esse padrão de políticas foi seguindo. As previsões de criação de institucionalidades, competências e mecanismos de descentralização constantes nas normativas das políticas nacionais tomaram rumos e graus de efetivação distintos. $\mathrm{Na}$ prática, aspectos como repasse fundo a fundo, implementação das ações previstas nos planos nacionais e fortalecimento de conselhos deliberativos não se concretizaram em todas as políticas setoriais.

A partir do segundo Governo Lula e primeiro Governo Dilma, identifica-se um movimento do governo central para 
fortalecer grandes programas federais - a exemplo do Programa Brasil sem Miséria, Programa de Aceleração do Crescimento, Programa Minha Casa Minha Vida -, que aportam montantes significativos de recursos federais e são formulados e geridos diretamente pelo governo federal, de modo geral, ao largo das institucionalidades previstas no âmbito das políticas nacionais. De maneira geral, esses programas inseremse em um contexto no qual o governo federal vem ocupando um papel de protagonismo no planejamento e na condução de grandes projetos, sejam eles relacionados aos megaeventos esportivos que serão sediados no país, ao desenvolvimento da rede de infraestrutura brasileira, ao enfrentamento do deficit habitacional ou à redução da pobreza.

Contudo, essas são apenas indicações de uma nova tendência característica dos últimos governos - inserida em um marco temporal não abarcado no âmbito da elaboração deste trabalho -, mas pode ser apontada como um movimento recente, que merece novas investigações.

\section{Referências}

Abrucio, F.L. (2005). A coordenação federativa no Brasil: a experiência do período $\mathrm{FHC}$ e os desafios do governo Lula. Revista de Sociol. e Política, Curitiba, 24(6), 41-67.

Almeida, M. Recentralizando a Federação? (2005). Revista de Sociol. e Política (24, 2940, jun). Curitiba.

Almeida, M. (2000). Federalismo e Proteção Social: a experiência brasileira em perspectiva comparada. São Paulo, mimeo.

Almeida, M. (1995). Federalismo e Políticas Sociais. Revista Brasileira de Ciências
Sociais, São Paulo, a.10.

Ariznabarreta K. (2001). Capital social, cultura organizativa y transversalidad en la gestion pública. In Congreso Internacional Del Clad Sobre La Reforma Del Estado Y La Administración Pública (6, 5-9 nov). Buenos Aires.

Ariznabarreta K. (2006). Métodos de constituição das instâncias decisórias Federalismo. In Reforma Política no Brasil. Belo Horizonte: Editora UFMG.

Arretche, M. (2012). Democracia, federalismo e centralização no Brasil. (Vol.1, 1 ed., 227 p.) Rio de Janeiro: Fundação Getulio Vargas/ Fiocruz.

Arretche, M. (2008, maio). Palestra apresentada ao Seminário do Departamento de Ciência Política da Universidade de São Paulo.

Arretche, M. (2005). Quem taxa e quem gasta: a barganha federativa na federação brasileira. Revista de Sociol. e Política (24, 69-85, jun). Curitiba.

Arretche, M. Federalismo e Políticas Sociais no Brasil: problemas de coordenação e autonomia. (2004). São Paulo em Perspectiva (Vol. 18, n. 2, pp. 17-26). São Paulo.

Arretche, M. (2002, September). Relações federativas nas políticas sociais. EDUC. SOC. (Vol. 23, n. 80, pp.25-48). Campinas.

Arretche, M. (1999, Jun.). Políticas Sociais no Brasil: Descentralização em um Estado federativo.) Revista Brasileira de Ciências Sociais - RBCS (a.14, n. 40, pp. 112-141) São Paulo. 
Arretche, M. (1996). Mitos da descentralização: mais democracia e eficiência nas políticas públicas? Revista Brasileira de Ciências Sociais (a.11, n. 31, jun). São Paulo.

Franzese, C. (2010). Federalismo Cooperativo no Brasil: da constituição de 1988 aos sistemas de políticas públicas. Tese de Doutorado. Fundação Getúlio Vargas. São Paulo.

Souza, C. (2005). Federalismo, desenho constitucional e instituições federativas no Brasil pós-1988. Revista de Sociologia e Política (n. 24). Curitiba.

Souza, C. (2004). Governos locais e gestão de políticas sociais universais. São Paulo Perspectiva (n. 18, v. 2). São Paulo.

Souza, C. (2002). Governos e sociedades locais em contextos de desigualdades e de descentralização. Ciência e Saúde Coletiva (Vol. 7, n. 3, pp.431-442).

Souza, C. e Carvalho, I. (1999). Reforma do
Estado, descentralização e desigualdades. Cedec (n. 48, pp.187-213). São Paulo: Lua Nova.

\section{Nota}

1 Esta seção se inspira e atualiza (com informações recentes disponíveis em sítios eletrônicos) parte do trabalho desenvolvido por Maria Hermínia Tavares de Almeida no artigo "Federalismo e Proteção Social: a experiência brasileira em perspectiva comparada", publicado (em versão mimeo) no ano 2000; o qual se insere no debate sobre o modelo federativo brasileiro, seus arranjos e distribuição de competências e atribuições entre as esferas de governo. A partir da sistematização de informações básicas sobre dispositivos legais e iniciativas descentralizadoras, a autora apresenta as competências dos níveis de governo nas diferentes áreas de políticas sociais - Atenção à Saúde, Assistência Social, Políticas Contra a Pobreza, Educação, Habitação, Saneamento Básico, Previdência Social, Meio Ambiente e Segurança Pública. Para tal, utiliza como periodização três marcos: Antes de 1988; Constituição de 1988 e Normas e Políticas Atuais (2000). 